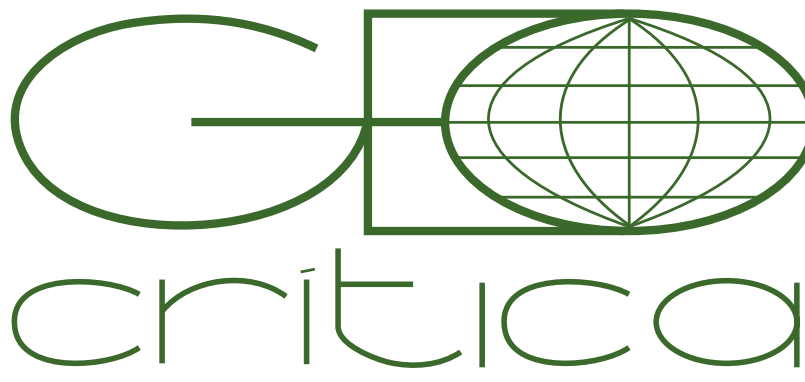

\section{Scripta Nova}

Revista Electrónica de Geografía y Ciencias Sociales Universitat de Barcelona

1 de agosto de 2018

\title{
CRONOTOPÍAS EN TORNO AL GÉNERO. MODOS DE INCORPORACIÓN DIFERENCIALES ENTRE "BANGLADESÍES" EN LAVAPIÉS
}

\author{
Juan R. Méndez Méndez \\ Universidad Nacional de Educación a Distancia (UNED) \\ juan_r_mendez@hotmail.com
}

\section{Cronotopías en torno al género. Modos de Incorporación diferenciales entre "bangladesíes" en Lavapiés (Resumen)}

Basado en un estudio etnográfico sobre las diferencias en los procesos de incorporación de migrantes "bangladesíes" en Lavapiés y las cronotopías que estos originan, el texto reflexiona sobre cómo enlazar el estudio de los modos de incorporación con una teoría del espacio que permita conceptualizar adecuadamente los procesos migratorios, alejándose del nacionalismo metodológico. A partir de esto, se ofrece una definición de los modos de incorporación que permita reflejar las particularidades migratorias que diferentes posiciones de sujeto brindan a partir de los condicionantes estructurales que influyen en la migración

Palabras clave: Migración; Género, Cronotopía, Espacio, Incorporación

\section{Chronotopies around the genre. Differential Modes of Incorporation among "Bangladeshi" in Lavapiés (Abstract)}

Based on an ethnographic study about the differences in the incorporation processes of "Bangladeshi" migrants in Lavapiés and the chronotopies that these originate, the text reflects on how to link the study of modes of incorporation with a theory of space that allows conceptualice properly migratory processes, moving away from methodological nationalism. From this, is offered a definition of the modes of incorporation that allows to reflect the migratory particularities that different subject positions bring from the structural conditioning factors that influence migration

Keywords: Migration; Gender, Chronotopia, Space, Incorporation 
"Bangladesh es Cuenca" me decía Luis, un trabajador social de Lavapiés en el verano del 2014. Hacía unos pocos meses que mi investigación sobre las condiciones de incorporación de migrantes "sin papeles" en el barrio había girado hacia aspectos relacionados con el género. La razón era la petición de Migrapiés, grupo de defensa de los derechos de la población migrante en el que participo desde 2011, de analizar por qué en el grupo un $80 \%$ del total eran hombres "africanos" y "bangladesíes" pero no acudían mujeres de estos orígenes. Esto había dirigido mi investigación a entornos donde confluían el género y lo "bangladesí". A través de conocidos comunes concerté una entrevista con Marta y Luis, trabajadores del ayuntamiento que realizaban intervención entre la población migrante del barrio. Y la respuesta de Luis venía motivada por mi pregunta sobre cómo veían ellos las relaciones que tenían los migrantes en Lavapiés con sus entornos de origen. Tras su afirmación, Luis ampliaba la respuesta:

Que es como si estuviera en Cuenca Bangladesh. O sea, en el sentido de que hay que esa cercanía... se siente tan cercano que, no es como si estuviera en la otra punta del mundo... se ve cercano en todos los sentidos. En el me voy y vengo para conocer a no sé quién, o porque mi madre esta mala... es decir, que en un momento dado se hace un esfuerzo por pagar un billete y volver. Y luego lo que pasa allí, pasa aquí y lo que pasa aquí se sabe allí, y lo que aquí pasa se organiza allí. (Extracto del diario de campo del autor)

Ya habíamos hablado de su experiencia de trabajo con mujeres "bangladesíes". Marta me decía:

La cultura bangla es una cultura con unos roles supermarcados y cosas que son propias de mujeres y cosas que son propias de hombres... ¡Ah! y luego, los espacios de sociabilidad son totalmente diferentes. Es decir, si queremos llegar a las mujeres, están en el parque, a la salida de los colegios... o sea, como que también tienen espacios, pero como aquí en muchos pueblos, que llegas al pueblo, te metes en la bar y no hay ninguna mujer, que tienen espacios de sociabilidad diferentes, tiempos diferentes y con roles muy marcados. (Extracto del diario de campo del autor)

Esta conversación con Luis y Marta, y sus visiones sobre lo "bangladesí", el espacio y el género introducen lo que trataré en este texto. Aquí mostraré diferentes procesos de incorporación de personas identificadas como "bangladesíes" en Lavapiés, analizando los condicionantes que género y espacio introducen en el proceso migratorio. A partir de esto, realizaré una reflexión sobre el espacio y los modos de incorporación desde la idea de que en torno a lo "bangladesí" se producen en Lavapiés incorporaciones diferenciales que acarrean diferentes desarrollos espacio-temporales, punto a partir del cual debatir sobre cómo determinadas metáforas espaciales contribuyen a generar reificaciones identitarias, de las que sería un ejemplo la imagen de la "cultura bangla" a la que aludía Marta. Frente a esto, propondré una visión espacial que, alejándonos del nacionalismo metodológico, la tendencia a clasificar a las personas en función de su nacionalidad o su origen ${ }^{1}$, pueda recoger lo diverso de diferentes trayectorias socio-espaciales. Una visión donde el espacio es

1 Levitt y Glick Schiller, 2004. 
visto como parte y condicionante de lo social. Con estos objetivos, utilizo el cronotopo como categoría analítica para acercarme al entrelazamiento de espacialidades y temporalidades, analizar las diferencias establecidas en torno al género y pensar formas de análisis que se alejen de la reificación del origen como principal elemento de clasificación identitaria, sustituyendo normatividades férreas asignadas a la procedencia por gradualidades sobre ciertas convenciones.

Al hablar de convenciones o normatividades, me estoy refiriendo a procesos de amplia difusión transmitidos hegemónicamente ${ }^{2}$ a partir de articulaciones complejas dentro de campos asociativos ${ }^{3}$ que procuran formas de sentido común. No hablo de obligaciones determinantes, sino de normas procesuales ${ }^{4}$ que son constantemente reformuladas, sometidas a debate, desafiadas... dado que se mueven en una tensión entre la tendencia a su objetivación dentro de relaciones desiguales de poder y la diversidad que originan las diferentes posiciones de sujeto que participan en este intento de objetivación. Un ejemplo de esto se ve en una afirmación que se repite con frecuencia en mis entrevistas en torno a lo "bangladesí": En Bangladesh las cosas son... sí, pero no todos... Muchas veces, con quienes hablo se esfuerzan en darme una visión coherente de lo que pasa en Bangladesh, pero cuando yo pregunto si lo que me acaban de contar es así, me contestan que no todo el mundo. Hace poco Nahir me decía que las mujeres en Bangladesh suelen llevar la cabeza cubierta como forma de modestia cuando salen a la calle y que trabajan en el hogar mientras los maridos llevan el sueldo a casa. Al preguntarle si esto es algo común en Bangladesh, me respondía que sí pero no, que en su país hay mucha gente y se hacen cosas muy diferentes. Las mujeres de su familia pueden salir con el pelo suelto, con un pañuelo sobre los hombros por si quieren cubrirse la cabeza, o a veces directamente con el pañuelo sobre la cabeza. También, me decía, hay muchas mujeres que trabajan y maridos que hacen las labores del hogar, dependiendo de quién, de la edad, de la familia, educación... Al detallarme el pero no todos, Nahir estaba estableciendo una descripción de diversidad dentro de un elemento convencional que es a la vez atractor categorial, pues para él Bangladesh está relacionado con ciertas costumbres y roles que incluyen convenciones sobre género y espacio. Pero estas normatividades no sirven fácilmente como resumen de toda la complejidad que cada persona vive en sus trayectorias vitales.

Estas convenciones pueden ofrecer un punto de partida para el análisis. Las percepciones de Nahir sobre una separación socio-espacial generizada coinciden con el discurso que me ofrecía Marta sobre lo "bangladesí" y sus roles. También con parte de mis propias observaciones durante el trabajo de campo, focalizado en Lavapiés y la relación entre lo "bangladesí" y Migrapiés: hay una tendencia, por ejemplo, a que la migración inicial sea masculina, generalmente en condiciones "irregulares", buscando mejorar las condiciones económicas familiares y "un sitio tranquilo en el que

2 Laclau y Mouffe, 1987.

3 Latour, 2008.

4 Díaz de Rada, 2012. 
vivir". Una vez establecidos económicamente y habiendo "legalizado" su estancia en España, vuelven a Bangladesh para casarse (y los que están casados para ver a su mujer e hijos) e intentan reagruparse con su familia, siendo la etapa en la que migra la mujer. Esta dinámica general, producida dentro de un alto grado de variabilidad, va a ofrecer procesos de incorporación diferenciales, ligados a normatividades sobre cómo deben ser las relaciones de género. Para analizar esto, he delimitado tres tipos diferentes de migración, indicando que más que tipos fijos, habría que hablar de gradualidades en torno a estas tipologías: primero la migración masculina "sin papeles", en situaciones de "irregularidad administrativa"; segundo, la migración femenina por reagrupación familiar con un alto grado de cumplimiento de las convenciones sobre la mujer "bangladesí" observadas en mi entorno de investigación; tercero, la migración femenina que, por la forma de migrar o por el proceso de incorporación, se aleja de estas normatividades.

Este texto está basado en una investigación etnográfica que llevo a cabo desde el año 2013, focalizada en el barrio de Lavapiés y centrada en procesos de colectividad y su relación con el género y el espacio en torno a Migrapiés. Cuando hablo de etnografía, me refiero a una construcción reflexiva de intersubjetividad donde cobra importancia la observación participante, un proceso, a la vez que una situación metodológica, que busca acceder a las lógicas presentes en el entorno de estudio a partir de la instrumentalización del investigador y de las relaciones sociales que este establece durante el trabajo de campo ${ }^{5}$. El desarrollo de esta investigación se ha realizado examinando diferentes núcleos de sociabilidad interconectados entre sí: partiendo de Migrapiés se han rastreado en lo empírico diferentes asociaciones en la cotidianeidad para llegar a otros ámbitos relacionados con el día a día de los participantes en el grupo, tales como pueden ser las mezquitas del barrio, las asociaciones de migrantes, los núcleos familiares, los entornos de origen en Bangladesh o las actividades públicas relacionadas con la migración o las "comunidades" presentes en el barrio. Todos estos lugares no se ven como puntos aislados de observación, sino como un conjunto relacional, un entramado asociativo complejo desde el que plantear una etnografía multisituada ${ }^{6}$ que ofrece la posibilidad de acercarse a cómo se construyen normatividades entre las personas presentes en el campo. Esto permite una aproximación a lo observado que, aunque parcial por necesidad y sujeta a la posicionalidad del etnógrafo, puede brindar un análisis metódico y riguroso de cómo se configuran los temas tratados en el entorno de trabajo.

Desde esta perspectiva, los resultados obtenidos parten de la convivencia cotidiana durante los cinco años que dura esta investigación, de compartir el hacer y el pensar reflexiva y metódicamente con las personas en el campo participando en diferentes actividades como forma de socialización que da acceso a la comprensión de las lógicas buscadas. A esto hay que añadir cerca de cuarenta entrevistas en profundidad, principalmente a personas migrantes en Lavapiés y participantes en mi en-

5 Velasco y Díaz de Rada, 1997.

6 Marcus, 1995. 
torno de investigación, pero ampliada a quienes por su posición en el campo podían aportar información referente al estudio (por ejemplo Luis y Marta, los trabajadores del ayuntamiento). Por último, esto se ha completado con la recogida de documentación (estadísticas, actas, publicaciones en redes sociales, fotografías...) de manera que la observación, las entrevistas y la documentación sirvan para triangular las interpretaciones realizadas sobre el material empírico para aplicar diferentes perspectivas al análisis ${ }^{7}$. En este proceso cobra especial importancia tanto el pertenecer a Migrapiés como el ser vecino del barrio. La construcción del campo relacional de trabajo a partir de estos condicionantes me ha permitido el acercamiento a mujeres que participan en diferentes movimientos sociales. Este hecho, como veremos a lo largo del texto, ya suele demarcar un alejamiento de determinadas convenciones delimitadas por lo "bangladesí. Pero mi posición en el campo también me ha posibilitado acceder aquellas mujeres que en contacto con el entorno estudiado (familiares o amigas por ejemplo), por diversas razones se muestran gradualmente más cercanas a las convenciones en torno a lo "bangladesí" observadas.

\section{Un pequeño vistazo a Lavapiés}

Aunque no puede limitarse el contexto de investigación a Lavapiés, ni pensar en una única historia del barrio, un breve repaso a ciertos hitos socio-históricos, en relación a su importancia para las dinámicas migratorias que aquí se analizan, pueden ofrecer un marco para situar el escenario principal donde se desarrolla mi argumentación: el barrio de Lavapiés. Situado al sur de la Puerta del Sol y administrativamente parte del barrio de Embajadores en el distrito centro de Madrid, Lavapiés se ha caracterizado dentro del imaginario madrileño como un barrio popular de gente humilde y clase trabajadora8. A mediados del siglo XIX Lavapiés se convierte en destino de multitud de migrantes llegados a Madrid desde todas partes de España. Dados sus escasos medios económicos y la marginalidad que caracteriza al barrio, estos migrantes habitan casas sencillas, muchas veces construidas sobre la marcha. En los años setenta del siglo XX se produce un proceso de envejecimiento poblacional y degradación de infraestructuras consecuencia del desplazamiento a la periferia madrileña de los hijos de los migrantes, el abandono institucional y el aumento en el barrio de la drogadicción. Esta situación empezará a cambiar a partir de 1990, con la llegada de la migración internacional y de jóvenes profesionales y activistas sociales que hacen del barrio su residencia mientras las administraciones madrileñas comienzan un extenso plan de rehabilitación barrial9. Todo esto da pie a un parque de viviendas heterogéneo, de distintas alturas y calidades donde un importante condicionante en la llegada al barrio de la migración internacional con menos medios económicos tiene que ver con las peculiaridades de Lavapiés: el parque de viviendas antiguo y sus características de barrio humilde ofrecen precios de

7 Velasco y Díaz de Rada, 1997.

8 Cañedo Rodríguez, 2011.

9 Cañedo Rodríguez, 2005. 
alquileres más bajos que otras zonas céntricas de Madrid, combinando la economía con la centralidad que el barrio otorga. Sus edificios y sus calles estrechas, irregulares y empinadas confieren a Lavapiés una topografía característica y un "aire de pueblo" que resaltan muchos de los que viven allí, mientras el barrio se construye como campo social de límites difusos, cambiantes y fluidos a partir de procesos de muy variada naturaleza y alcance que le unen inextricablemente a desarrollos hegemónicos de diferente alcance y cualidad, tal y como veremos en los condicionantes de la migración "bangladesí" al barrio. Como parte de Madrid, las dinámicas de la ciudad, a su vez enlazadas a otras más amplias, se imbrican con Lavapiés, demarcando unas características que, si bien se concretan en el contexto barrial, no pueden considerarse como autoproducidas y autocontenidas.

Madrid se ha convertido en los últimos años en una de las poblaciones españolas que mayor número de migrantes internacionales ha recibido durante el periodo de auge económico ${ }^{10}$, si bien esta llegada se ha visto frenada a partir de la segunda década del siglo XXI, a medida que empeoraba la situación económica en el estado español. A modo de referencia, según datos del Instituto Nacional de Estadística (INE), en 2001 había en España 1.737.972 de extranjeros, mientras que en 2017, la cifra ascendía a 4.464.997, llegando a ser de 5.269.458 en 2013. El distrito centro de Madrid es, a su vez, aquel donde se concentra el mayor número de estos migrantes ${ }^{11}$, destacando en concreto Lavapiés, con una población de cerca de 45.000 habitantes y donde en 2013 un $31 \%$ de sus pobladores era "extranjero" y convivían ochenta y ocho nacionalidades ${ }^{12}$. Según datos del INE, en la Comunidad de Madrid vivían, en 2003, 2.609 personas nacidas en Bangladesh. En 2014, la cifra se había incrementado a 4.717 de un total de 13.211 en todo el estado español, mientras la migración "bangladesí" se focalizaba principalmente en Madrid y Catalunya ${ }^{13}$. De los residentes "bangladesíes" en Madrid, en 2014, 2.646 estaban empadronados en el distrito centro (principalmente en el barrio de Embajadores) con un 84\% de hombres sobre el total. En 2017, la población nacida en Bangladesh en el distrito centro era de 2.592 sobre un total de 5.576 en la ciudad de Madrid, según el censo del Ayuntamiento, de las cuales un $82 \%$ eran hombres, lo que apunta a un asentamiento permanente más allá de los ciclos económicos, a una migración masculinizada y a un lento crecimiento de la presencia de mujeres a medida que estas llegan por reagrupación familiar.

\section{La migración desde Bangladesh}

Decía antes que la migración "bangladesí" tiene que ver tanto con la situación económica, como con la búsqueda de "tranquilidad". Para entender los condicionantes que influyen en la decisión de migrar resumiré brevemente la historia de Bangla-

10 Dirección General de Inmigración, 2009.

11 Pineda et al., 2011.

12 Carretero, 2013.

13 En Catalunya residían en 20145.732 personas nacidas en Bangladesh, principalmente en Barcelona. 
desh, que fue colonia inglesa hasta 1957, cuando tras la descolonización territorial pasa a formar parte del recién creado estado de Pakistán. Pero la desatención del gobierno pakistaní y el intento de establecer el urdu como idioma nacional desatan un movimiento independentista que desemboca en 1971 en una guerra de independencia y la constitución de Bangladesh como estado. Desde entonces, Bangladesh se caracteriza por el conflicto social y una importante tradición de intervención militar en los asuntos políticos: de los poco más de 40 años de existencia, el estado ha sido gobernado 16 años por juntas militares. A esto se suman los desastres acarreados por el clima, con abundantes monzones e inundaciones y la falta de infraestructuras como carreteras o centrales hidroeléctricas, con frecuentes cortes de luz en el país. Esto hace que Bangladesh esté entre los países más pobres del mundo ${ }^{14}$, con un $31 \%$ de la población viviendo en situaciones de pobreza ${ }^{15}$ y dependiente de ayudas a la cooperación que condicionan sus políticas y mantienen al país con una fuerte deuda externa y con importantes carencias en los servicios públicos. Por ejemplo, la atención sanitaria pública es escasa, con pocos recursos y falta de medicinas, ante lo cual, muchas personas acuden a personal no especializado o a servicios privados ${ }^{16}$.

La migración Bangladesh-Lavapiés no se suele dar entre las personas más pobres. Es habitual la presencia de universitarios entre los migrantes con los que he hablado. También de personas con cierta estabilidad en Bangladesh que querían mejorar su situación, ocasionada por los problemas existentes en su país. Por ejemplo Ali, que cuando su empresa empezó a ir mal, decidió venir a probar suerte. $\mathrm{O}$ Kamal, que tenía trabajo con su padre en el comercio familiar, pero sentía que era una carga para sus padres y que necesitaba mejorar. En estas decisiones aparece un aspecto que influye en la concepción hegemónica que entre los "bangladesíes" en Lavapiés se tiene del asentamiento en Europa: la migración a Gran Bretaña. La llegada de los primeros "bengalíes" ${ }^{17}$ a Gran Bretaña se produce a partir de su trabajo como marineros en los barcos comerciales británicos durante el periodo colonial a finales del siglo XIX y principios del XX. El incremento de esta migración se produce en los años 50 y 60, potenciada por la necesidad de mano de obra en la industria británica tras la II Guerra Mundial y las facilidades ofrecidas por el gobierno británico a la llegada de trabajadores de los ámbitos coloniales. Y llega principalmente desde la zona rural de Sylhet, provincia bangladesí, buscando mejorar la situación económica familiar ${ }^{18}$. En los años 70 y 80, la crisis económica y los despidos en el sector industrial hacen que estos "bangladesíes" de Sylhet comiencen a trabajar en el sector textil o en restaurantes, aumentando a su vez el número de reunificaciones familiares mientras quienes habían migrado se reúnen con las mujeres e hijos que estaban en Bangladesh. Esto va a influir en los cambios en los entornos de destino, apare-

14 Hasan, 2012.

15 Ministerio de Asuntos Exteriores y Cooperación, 2013.

16 Faiz Rashid et al., 2006.

17 Uso la definición identitaria previa a la creación de Bangaldesh, correspondiente a la provincia de Bengala, actualmente separada en dos; una provincia de la India y el estado de Bangladesh.

18 Eade, 2006; Gardner y Ahmed, 2006. 
ciendo mezquitas, tiendas de comida halal e instituciones de enfoque "bangladesí"19 que convierten Gran Bretaña en una referencia hegemónica en la migración desde Bangladesh a partir del éxito obtenido por quienes migraron allí: Sylhet se ha convertido en una de las regiones más prosperas del país debido a las remesas enviadas por los migrantes y la inversión que estos han hecho ampliando sus casas familiares y ayudando a la familia a progresar ${ }^{20}$. Este proceso produce una analogía sobre las posibilidades de la migración a otras partes de Europa a medida que las restricciones en las políticas migratorias se acentúan en Gran Bretaña ${ }^{21}$ mientras las situaciones socio-económicas de otras regiones europeas incrementan la posibilidad de migración. Así, es común referirse a la "pasta" que tienen los de Sylhet a la hora de hablar de los motivos de la migración, siendo la mejora familiar el eje principal en la vida de muchos de los migrantes "bangladesíes" en Lavapiés. Es lo que me cuenta Alal:

Por ejemplo yo vengo aquí para mejorar la vida. Cuando pueda ir a Bangladesh yo caso y traigo mi familia. Toda la gente tiene como así su sueño, que un día puede venir aquí, montar un negocio para mejorar la vida, porque toda la gente, todas las personas de Bangladesh hay responsabilidad para su familia. No como en Europa, que yo gano dinero sólo para mí. Persona de Bangladesh gana dinero sólo para su familia. Por ejemplo, mi padre, trabaja hasta cincuenta y ocho años. Él trabaja sólo para nosotros, él gana dinero, gasta dinero en nosotros... Ahora tengo turno mío, porque yo soy mayor. Mi padre no trabaja ahora. Él como es mayor no puede trabajar, por eso ahora tengo que dar dinero para mi familia. (Extracto del diario de campo del autor)

A la migración desde Sylhet a Gran Bretaña como signo de éxito, se unen además la tendencia en Sudasia a migrar como solución a los problemas económicos, el impacto que las remesas tienen en los entornos de origen ${ }^{22}$ y la costumbre de las elites "bangladesíes" de viajar, comerciar o estudiar en Europa o Estados Unidos²3, otro factor en la formación de significados de alta difusión sobre posibilidades y procesos migratorios. Pero la economía no es el único condicionante a la hora de pensar en la migración. La mejora de las condiciones económicas se interrelaciona de diferentes formas con la búsqueda de una vida más "tranquila", generalmente dependiendo de la conflictividad de la región de procedencia y de las experiencias en esta región. Alal, se marchó de su ciudad por un problema con los partidarios de un partido político que hicieron que temiera por su vida. También Mohamed refiere motivos similares. Estando en una feria en Europa, representando a la empresa informática para la que trabajaba, su padre le dijo que se quedará allí, que había habido un cambio de gobierno en su región y este estaba tomando represalias sobre los partidarios del anterior gobierno. Nahir no tuvo ningún problema político, pero muchas veces habla de la cantidad de "gente mala" que hay allí por la "gran cantidad de pobreza". La alternancia en el gobierno entre los dos principales partidos políticos del estado bangladesí, Bangladesh National Party y Awami League, viene acompañada de

19 Gardner y Ahmed, 2006.

20 Gardner y Mand, 2012.

21 Gardner y Ahmed, 2006.

22 Jawaid y Raza, 2016.

23 Ministerio de Asuntos Exteriores y Cooperación, 2013. 
desapariciones, represalias y violentas huelgas llamadas hartales, que generalmente acaban con decenas de muertes por ambos lados ${ }^{24}$. Y la administración se convierte en otro factor del miedo. Ahmed, que recientemente visitó su país, comentaba "ese es un sitio sin ley... y si te pasa algo, ¿a quién vas a llamar? Si la policía es la peor". $\mathrm{Ara}^{25}$ señala que las agencias policiales y el ejército son a menudo acusadas de abusos de poder y violación de los derechos humanos, incluida la tortura o la extorsión. A esto se añade la situación constante de colapso de las instituciones relacionadas con el mantenimiento de la ley. Es común la corrupción entre miembros de la policía y otras agencias estatales, ganando dinero mediante la extorsión para el beneficio propio o realizando servicios ilegales para políticos. La detención arbitraria es habitual y suele acompañarse de asalto y en algunos casos de torturas e incluso asesinatos. Miembros de partidos políticos de la oposición suelen ser arrestados sin motivo y sometidos a torturas. Las autoridades intentan impedir las manifestaciones deteniendo previamente a los activistas políticos, y aquellos que finalmente se manifiestan suelen ser lesionados, o incluso asesinados, en choques con la policía o contra manifestantes del bando contrario ${ }^{26}$. Dice Mohamed:

No solo tiene problemas la policía. Policía y grupos de partido popular. Tiene dos políticos, si la gente entre ellos se pelea, la gente se mata directamente con armas, con pistola, con bombas... todo eso puede ser. También puede ser: tú tienes negocio, si tú no pagas la dinero, 1.000 o $2.000 €$, después la gente hace secuestro y te lleva luego a un piso para decir: paga 50.000 $€$. Si tienes pasta, paga 50.000, si no tienes pasta, paga menos. Eso también haciendo ahora mismo. Ahora mucha gente tiene bastante miedo, no quiere ir a mi país. (Extracto del diario de campo del autor)

Así pues, la "mejora" buscada en la migración tiene que ver con lo económico y, a la vez, con la "tranquilidad", siendo Europa una posibilidad de conseguir ambas cosas para el conjunto familiar. Y esta descripción de la migración desde Bangladesh, sus motivos, formas de migrar y centralidades en torno al proyecto migratorio encajan con la línea que desarrolla Portes ${ }^{27}$ a partir de la crítica a los modelos que explican la migración únicamente desde aspectos económicos y diferencias salariales. Estas teorías no explicarían la variabilidad en la migración desde diferentes lugares ni la frecuencia de las migraciones entre estados donde el receptor ha tenido lazos coloniales, económicos o culturales previos (por ejemplo la migración desde Bangladesh a Gran Bretaña ${ }^{28}$. Otro defecto que Portes observa a estas teorías es la incapacidad para explicar por qué la gente se queda una vez los motivos económicos han desaparecido. Es decir, no se tendría en cuenta lo social de la migración ni cómo las redes creadas conectan diferentes personas en campos espaciales, creando apoyos entre migrantes, transmitiendo información y ayudando en el asentamiento en el destino migratorio, haciéndolo relativamente independiente de los ciclos eco-

24 Gijon Prieto, 2012.

25 Ara, 2015.

26 Gijón Prieto, 2012; Mato, 2006.

27 Portes, 1981.

28 Portes y Böröcz, 1989. 
nómicos ${ }^{29}$. Más que el beneficio económico, sería la inserción en redes sociales en permanente contacto lo que mantendría la migración en el tiempo y explicaría los diferenciales en desplazamientos y caracteres migratorios ${ }^{30}$.

A partir de esta crítica, Portes ${ }^{31}$ introduce la categoría modos de incorporación para analizar las diferentes formas de llegada de los migrantes a su destino y los principales factores que influyen en este proceso, clasificados como condiciones de salida, clase en el origen y contexto de recepción ${ }^{32}$. No todo migrante tiene que serlo por cuestiones laborales y sus motivaciones y condiciones de salida afectarán a la incorporación. Además, se originarán diferentes contextos de recepción a partir de aspectos económicos, políticos o legales, donde habría que contemplar políticas gubernamentales, el mercado laboral, la población "nativa" vecina y la "comunidad" propia ya pre-establecida ${ }^{33}$. Las diversas posibilidades de incorporación delimitadas por estos factores contribuyen a señalar la diversidad de formas de asentamiento y ofrecer una mayor precisión analítica que combine las perspectivas y trayectorias comunes de los migrantes con los factores estructurales que les competen.

\section{Cronotopías de género Incorporación de "sin papeles"}

La definición de Portes nos sirve como orientación para analizar el primer prototipo de incorporación que voy a describir. Nahir llegó a Lavapiés con una visa de turista comprada en Bangladesh tras una fuerte inversión familiar. Recuerda que los primeros tiempos fueron muy difíciles: no sabía nada, ni el idioma, ni dónde comprar comida; ni cómo "regularizar" su situación de "ilegalidad" que le impedía trabajar, dada la legislación española en materia de migración y trabajo. Tenía algunos conocidos en el barrio, con los que se quedó a vivir y formó su primer núcleo social en Lavapiés. A partir de ellos participó en algunos colectivos de "bangladesíes", donde se enteró de la existencia de Migrapiés, grupo en el que empezó a participar y desde dónde se le apoyó para conseguir los "papeles". Luego pudo dejar su trabajo vendiendo latas de cerveza y empezó a trabajar muchas horas en la frutería de un "paisano" para poder mandar dinero a casa, su principal preocupación junto a la de conseguir dinero para montar un negocio propio y luego volver a Bangladesh, casarse y traer a su mujer a España.

Dada la lejanía física entre España y Bangladesh, y la corrupción administrativa "bangladesí, que facilita la compra de visas si se tiene suficiente dinero, el camino migratorio suele ser llegar a Europa con visado temporal de turista o estudios. Esto supone una inversión económica considerable (alrededor de unos $15.000 €$ ) que dificulta la migración de los más pobres y supone un considerable gasto para la mayoría de quienes migran, originando esfuerzos familiares y deudas que se esperan

29 Portes y Böröcz, 1989.

30 Portes y Böröcz, 1989.

31 Portes, 1981.

32 Portes, 1981; Portes y Böröcz, 1989.

33 Portes y Böröcz, 1989; Portes y Rumbaut, 1996. 
solventar en el destino por las posibilidades que otorga la migración a Europa. Estos planes se dificultan por la condición de migrante "irregular", lo que conlleva riesgo de deportación y dificultades para encontrar trabajo "legal". Todo esto es previamente sabido por los migrantes "bangladesíes": tendrán que pasar unos primeros años difíciles hasta que las cosas mejoren, conocimiento obtenido por la información que facilitan los que han llegado primero. Kamal, por ejemplo, habló con un amigo para informarse de cómo iban a ser las cosas:

Pensando yo voy a Europa, porque un poco de bien, cuando voy. La gente 5, 6 años vives aquí, luego puedes tener carnet y residencia. A otro nuestro amigo vive en Italia, dice esto sistema por ahí. Por eso pensando una noticia bien, pero... amigo dice que España e Italia, Portugal... hace uno sistema de residencia, la gente papeles, pero dinero esto tampoco ganando. (Extracto del diario de campo del autor)

La transmisión de información también condiciona la elección de destino. En el asentamiento en Lavapiés confluyen la presencia de "paisanos" que pueden ayudar en la incorporación y las posibilidades de regularización que en la pasada década brindaba la situación económica estatal, enmarcada por las regularizaciones efectuadas por el gobierno en 2005 al hilo del crecimiento económico y la necesidad de mano de obra, sobre todo relacionada con la construcción. Mohamed lo intentó primero en varios estados europeos hasta que las facilidades de regularización le hicieron decantarse por venir a Madrid. Comenta:

Porque yo he conocido en Francia un amigo y dice: ¿por qué no hace un asilo de Francia? Ah bueno, ¿cómo puedo? Y yo he hecho una formulario de asilo. Y después, bueno, mala suerte, no consigo papeles. Yo, cuando otra vez aquí en Lavapiés, la regulación de 2005, yo estar aquí, porque en España dice si alguien tiene antes de agosto, si tiene ahí algún documento puede pedir en España para papeles, porque Lavapiés es una como... terminal, es como... como segunda capital de Dhaka aquí. Porque la gente viene, los inmigrantes sabe aquí Lavapiés vienen bastante los bangladesí, por eso información dónde puede ir. Por ejemplo Barcelona, Santa Coloma tiene bangladesí mucha gente. Si alguien quiere Barcelona ir, van a ir primero a Santa Coloma, por eso tú tiene información, porque ellos no saben idioma, porque es un idioma de... castellano, no sabe. Nosotros segunda lengua English, por eso nosotros no hablar español muy bien. Voy a Lavapiés, entonces la gente información, tiene informar dónde ir, dónde puede, cómo puede ir. (Extracto del diario de campo del autor)

Las redes de "paisanos" son las que facilitan el proceso de incorporación en el barrio. No como una demarcación genérica hacia lo "bangladesí", sino a partir de conocidos, amigos o amigos de amigos que acogen, ayudan y orientan a los recién llegados. Es común que los migrantes compartan piso con otros con quien les unía algún lazo previo a la migración. Por ejemplo Alal, que era amigo de la infancia de Ahmed y cuando llegó a Lavapiés comenzó a vivir con él y otros "paisanos" que Ahmed conocía previamente o que había conocido ya aquí, dado que a partir de estos primeros contactos se establecen nuevas relaciones que incrementan las redes de asociaciones entre "paisanos" en Lavapiés. Esto encamina la sociabilidad hacia lo "bangladesí" a partir de la ayuda mutua, el idioma común y la significación de unos orígenes culturales compartidos, algo que se amplía a otros entornos donde se pro- 
duce la confluencia de estos elementos, como la mezquita, que actúa como elemento de reunión y punto de información donde conocer a otras personas, o enterarse de posibles trabajos o estrategias de incorporación. También colectivos en torno a lo "étnico", como los de bangladesíes en España, o las sedes de los diferentes partidos políticos bangladesíes cumplen funciones semejantes, conformándose como núcleos de sociabilidad que, a la vez, contribuyen a las articulaciones transnacionales en torno a diferentes categorías, como pueden ser la religión y la transmisión de significados hegemónicos en torno a la "musulmanidad" a partir de la visita de autoridades religiosas de otros lugares del mundo. O la participación en la política bangladesí, ya sea protestando por la situación política de Bangladesh o participando en la campañas electorales del país. Esto va a establecer diferentes vínculos transnacionales dentro de los cuales también hay que contar con los contactos frecuentes con familiares y amigos que están en Bangladesh u otros lugares del mundo a través de internet, whatsapp o teléfono.

Pero existen otros tipos de sociabilidades encaradas hacia lugares no "étnicos" y que también están entrelazadas con el proceso de incorporación. Es el caso de Migrapiés. El contexto de recepción origina vulnerabilidades entre los "sin papeles bangladesíes": la imposibilidad de entrar en el sistema "legal" de trabajo español encamina, aconsejados dentro de las redes de "paisanos", a la venta ambulante, generalmente latas de cerveza en las zonas de ocio nocturno de Madrid o mercadería de broma, como sombreros, gafas graciosas y cosas por el estilo. Esto implica una venta "ilegal" y altas posibilidades de encontrarse con la policía municipal y ser multados. Además, la condición de "irregularidad" y la apariencia física facilitan la posibilidad de ser detenidos en la calle por la policía nacional, en controles por perfil étnico que acaban con el migrante en comisaría hasta 72 horas, una orden de expulsión y la posibilidad de acabar recluido en un Centro de Internamiento para Extranjeros. Estos procesos judiciales se complican por las dificultades con el idioma y el desconocimiento del sistema penal español, frente a lo cual muchos migrantes, generalmente aconsejados por sus "paisanos" que conocen o ya participan en ellos, recurren a diferentes grupos de defensa de derechos de la población migrante para solicitar apoyo ante sus problemas. En Migrapiés, esta solicitud de apoyo viene, en muchas ocasiones, acompañada por la decisión de participar en el grupo como forma de defenderse ante futuros problemas y ayudar a otros en la misma situación.

Las orientaciones "no étnicas" también se originan en el contacto con otros entornos, por ejemplo en las clases de castellano, donde se producen encuentros con personas de diferentes lugares, con lo que se pueden generar relaciones de compañerismo o amistad. $\mathrm{O}$ en el trabajo de vendedor ambulante, como comenta Alal:

Con barrio de la Latina, y vendiendo en la calle por la noche, ahora conozco mucha gente, y por eso siempre hablamos en la noche. Pero antes, no [...] Españoles, latinos, hace 4-5 años por el barrio vendiendo de latas, por eso. (Extracto del diario de campo del autor) 
También en el contacto cotidiano, con vecinos, en tiendas... se producen asociaciones que tienden a generar procesos de colectividad no encaminados a la "nacionalidad" a medida que el proceso de incorporación modifica las redes de asociaciones previas y estas influyen en el proceso de incorporación, generando redes y espacio-tiempos de sociabilidad específicos y procesos de colectividad en diferentes grados e intensidades a partir de diferentes características (lo "bangladesí, pero también ser de Migrapiés, amistades...). Así, el espacio-tiempo se introduce como elemento donde encontrar variabilidad posicionada a través del análisis del despliegue de redes de asociaciones en diferentes núcleos de interacción, es decir, del entramado de acciones de carácter heterogéneo que las personas realizan para relacionarse con otras. Por ello, al estudiar el proceso de incorporación, podemos analizar el campo asociativo concreto en el que cada migrante se mueve y cómo esto permite la adopción de formas de incorporación específicas donde elementos como los que se refieren a las perspectivas migratorias o a las políticas gubernamentales se contextualizan de diferentes maneras. Y este campo asociativo adopta a su vez una determinada forma espacial mientras conecta diferentes particularidades situadas geográficamente, lo que permite examinar lo local a partir de redes que conectan diferentes localizaciones y donde se ponen en relación territorio, subjetividad y movimiento social colectivo ${ }^{34}$.

Pero al hablar de espacio no me refiero únicamente a distribución geométrica en el territorio. El espacio no es sólo el lugar por donde se transita, sino producto y productor de lo social mientras lo físico y lo simbólico del espacio se entrecruzan produciendo formas concretas de vivir y surcar lo geográfico en relación con las redes de asociaciones en las que se participa. Así, el análisis del espacio lo haremos considerando el entrelazamiento de diferentes elementos y su contextualización en diferentes particularidades. Y espacio englobaría:

...distancia y diferenciaciones en la medición, en las connotaciones y en la apreciación de la distancia. Incluye movimiento. Incluye diferenciación geográfica, la noción de lugar y de especificidad y de las diferencias entre lugares. E incluye el simbolismo y el significado que se vincula a todas estas cosas en diferentes sociedades y en diferentes partes de estas sociedades $^{35}$.

Estos elementos se encuentran en las historias de incorporación de los "sin papeles bangladesíes" en Lavapiés: lo físico del espacio y la diferenciación geográfica los vemos en el coste de la migración a España y en la sensación de separación con los familiares, mientras la reformulación de las redes familiares demarcan puntos específicos de España y Bangladesh, no subsumibles a los estados nación ni a visiones espaciales de contenedor ${ }^{36}$. El movimiento y las restricciones en este se intersectan con cómo es vista Europa, con la forma de migrar y de estar en Lavapiés (el miedo a las redadas policiales) y también con la forma de entender Lavapiés como

34 Vertovec, 1999.

35 Massey, 2012a, 103.

36 Pries, 2005. 
lugar, dentro de asociaciones específicas no contenidas en un territorio que ayudan a dar sentido al barrio desde posiciones concretas de relacionalidad. Todo esto pone en relación las características espaciales, y su contextualización en diferentes posiciones de sujeto, con las redes de asociaciones y su distribución geográfica específica, permitiendo un análisis espacial que engloba tanto la forma espacial de lo social como la influencia de lo social en la formación de espacialidades diferenciales.

Esto nos acerca a una de las principales teorizaciones sobre los modos de incorporación: el transnacionalismo, que surge como una forma de cubrir las problemáticas de las teorías asimilacionistas, desviando la atención de las fronteras nacionales y la sociedad contenida por estas hacia instancias transfronterizas que ligan países de origen y destino ${ }^{37}$, redefiniendo los clásicos conceptos en torno a la incorporación, llamando la atención sobre el nacionalismo metodológico y definiendo procesos que no van a estar contenidos en los límites nacionales ${ }^{38}$, analizando cómo la movilidad de los migrantes entrelaza de diferentes maneras aspectos sociales, económicos y políticos ${ }^{39}$. Estas dinámicas migratorias contribuyen a la diversificación en los entornos receptores y producen culturas transnacionales a través de las cuales los migrantes mantienen múltiples vínculos con el origen ${ }^{40}$, produciendo redes transnacionales que facilitan la incorporación, condicionadas a su vez por las dinámicas que los migrantes afrontan en su destino. Pero Vertovec ${ }^{41}$ avisa sobre el problema de tratar el transnacionalismo en abstracto, sin prestar atención a lo concreto, a los cambios producidos en la cotidianeidad y a los condicionantes que produce el capitalismo global. Glick Schiller y Çağlar ${ }^{42}$ se centran en las sociabilidades cotidianas entre recién llegados y residentes locales y en la construcción conjunta de relaciones en la localidad, el lugar de trabajo y las instituciones. Para estos autores, la cotidianeidad ofrece una visión que muestra multiplicidad y diversidad, alejando narrativas dominantes sobre "culturas étnicas". Glick Schiller y Çağlar indican que las respuestas metodológicas a los problemas de las lentes étnicas se encuentran en el estudio del espacio urbano y las relaciones que se dan allí, ya que la geografía importa y es necesario mostrar las diferentes condiciones y escalas del espacio, estudiando los barrios como lugares donde las interacciones provocan cambios en las identidades y los comportamientos dentro de campos sociales específicos que transcienden las fronteras de un barrio o un estado nación. Los "sin papeles bangladesíes" en Lavapiés hacen "suyo" el territorio a fuerza de habitarlo, estableciendo diferentes redes de asociaciones en el proceso de llegada al destino, pero esto no significa que podamos ampliar estas experiencias a cualquier punto del estado español, o que el campo relacional pueda ser delimitado geográficamente al territorio de destino. Como hemos visto, las redes de asociaciones engloban diferentes puntos geográfi-

37 Monetti, 2017.

38 Vargas, 2017.

39 Portes, 2005, citando a Basch et al. 1994.

40 Sánchez Molina, 2005.

41 Vertovec, 1999.

42 Glick Schiller y Çağlar, 2016. 
cos que influyen de diferente manera en sus vidas: desde el pueblo de Bangladesh donde está su familia a la migración "bangladesí" a Londres; desde las relaciones con los compañeros de piso en Lavapiés a los mensajes de amplia difusión sobre la "musulmanidad"; desde relaciones vecinales "mezclando" orígenes a amigos que están en otros puntos de Europa o Asia. De las políticas migratorias españolas y europeas a las del gobierno de Bangladesh. O de la necesidad de vivir en Lavapiés (alquilar un piso, trabajar, enviar dinero a casa...) a las condiciones macroeconómicas y la geopolítica a escala mundial cuyas consecuencias les afectan directamente ${ }^{43}$.

\section{Incorporación de las mujeres}

Begun migró a Lavapiés, junto con su madre, por reagrupación cuando el padre pudo asentarse en el barrio, conseguir los "papeles" y abrir una pequeña tienda de alimentación donde ella ayuda mientras sigue viviendo con su familia. Considera que las "bangladesíes" en el barrio no suelen tener problemas:

Vienen a trabajar con sus maridos, no vive solas, no tienen problemas... mujeres, amigas aquí. Si alguien no sabe llama a otra que sabe para viaje, salir, ayudar, no tiene ningún problema. Las mujeres tienen papeles porque todas vienen con los maridos. (Extracto del diario de campo del autor)

Cuando le pregunto si la mayoría de mujeres que ella conoce llegan por reagrupación, me dice:

Llegan por reagrupación, ¿sabes? La mujer sola muy difícil. Muy difícil estar aquí sola... senegaleses cerca, pero mi país lejos y no pueden entrar las mujeres solas, muy peligroso. Senegal es cerca. Pero mi país difícil, por eso... nadie así. Una, dos, a veces. (Extracto del diario de campo del autor)

Begun comenta que no suele salir mucho. Vive con la familia y a veces da paseos con alguna de sus "paisanas". Se ocupa de la casa y de ayudar en la tienda de su padre. Su madre hace actividades similares y se encarga de los hermanos pequeños: los lleva al parque, al colegio... No habla demasiado castellano. Quiere aprender más pero no encuentra un lugar donde hacerlo. También por reagrupación llegó Aswini, tras su marido que migró unos años antes y que se dedica a cuidar de la casa y sus hijos. O Nazma, que fue primero a Barcelona, donde estaba su esposo.

Las dinámicas producidas en la migración de los "bangladesíes sin papeles" hacen que estos se muevan para conocer su nuevo entorno: relacionarse, conseguir casa y comida, aprender qué hacer para ganarse la vida y "mejorar". Todo esto les enfocará hacia determinadas redes de asociaciones y hacia trayectorias espacio-temporales concretas, como por ejemplo la mezquita a la hora del rezo, la venta ambulante (sobre todo los fines de semana, cuando más se vende), la administración o reuniones de colectivos donde encontrar amistades o ayuda en su incorporación. Parte de estos trayectos espacio-temporales tendrán que ver con personas que no son "bangladesíes" lo que puede facilitar la soltura con el castellano y la posibilidad

43 Hasan, 2012. 
de ampliar su sociabilidad a diferentes campos asociativos no "bangladesíes". Por otro lado, la mujer llega cuando el marido ha superado las primeras etapas migratorias y puede solicitar la reagrupación. Esto origina diferencias con la incorporación de los hombres: llegan en una etapa en la que "buscarse la vida" ya no es tan necesario. La situación de "regularidad" y la presencia del marido enfocan la sociabilidad de estas mujeres hacia la familia y otras amistades a partir de las redes de "paisanos" de los maridos, siendo frecuente un menor contacto con la población no "bangladesí" y generando una mayor dificultad en el manejo del castellano, lo que retroalimenta la orientación de la sociabilidad hacia a los "paisanos".

A estas dinámicas también contribuye la existencia de convenciones que establecen roles generizados. Chandra dice sobre Bangladesh:

El tema de las mujeres, por ejemplo, ahora se está desarrollando mucho, pero... es como que la mujer sólo puede quedarse en casa. No puede hacer otras cosas. Hay chicas que sí que están estudiando en la universidad y son gente que tiene... visión de futuro, pero hay otras que no las dejan elegir... hay algunas cosas que se parecen. Por ejemplo, aquí antiguamente el hombre iba a trabajar, las chicas en casa. Allí todavía se sigue manteniendo eso. Pero hay mujeres que ya trabajan. (Extracto del diario de campo del autor)

\section{Por otro lado, Nazma comenta:}

Hay zonas, sobre todo el campo, donde están muy atrasados, un poco como aquí. También el trabajo. Aquí en España hay muchos tipos de trabajo, que... en Bangladesh no tanto. En Bangladesh además, muchas mujeres no trabajan. Sobre todo en el campo, donde con lo que ganan los maridos es suficiente. Además no hay mucho trabajo, aunque depende de las carreras. En la educación, muchas mujeres hacen el instituto, el bachillerato, pero luego se casan y lo dejan: "tengo mi marido, mi vida para él". Aunque hay de todo. Luego ciertos trabajos no se pagan. Aquí, el cuidado de niños se paga. Allí, generalmente lo hacen amigas, familiares... aunque más en el campo que en la ciudad. (Extracto del diario de campo del autor)

Aunque las palabras de Chandra y Nazma apuntan a la diversidad y lo procesual, también marcan una convención hegemónica que origina una tendencia normativa hacia la separación de roles: el marido trabaja y la mujer cuida. La relación de la mujer con el cuidado y su relación con la construcción de objetivaciones sobre lo "bangladesí" ha sido analizado por Mookherjee ${ }^{44}$ que indica que la nación "bangladesí" es simbolizada como femenina a partir de la retórica de la tierra madre ligada a la idealización de los paisajes rurales y la esencialización de los roles de las mujeres. Mookherjee señala la amplia difusión en Bangladesh de la analogía mujer-madre, construcción que abre una vía que cuestiona la dicotomía que dirige a las mujeres al espacio privado para, desde el cuidado de la familia, mostrarlas como importantes para la comunidad. Rozario ${ }^{45}$ subraya la importancia del matrimonio en Bangladesh, muchas veces considerado como el paso a la adultez: con frecuencia el único estatus socialmente aceptado para las mujeres maduras es ser madre o esposa. Para Rozario, las mujeres siguen manteniendo unos patrones dirigidos principalmente al matrimonio y el cuidado de la familia, aunque esto no significa que

44 Mookherjee, 2011.

45 Rozario, 2007. 
no dispongan de agencia o que las relaciones marido-mujer no puedan desarrollarse de maneras diferentes y flexibles. La diversidad entre mujeres "bangladesíes" es analizada por Chowdhury ${ }^{46}$, señalando las diferencias entre mujeres en función de clase, geografía, estatus, etnicidad y racialización entre otras. Esta autora señala la importancia y extensión del patriarcado en Bangladesh y su influencia en las mujeres y su cotidianeidad, indicando que no hay un solo patriarcado, sino múltiples concreciones que acarrean diferentes situaciones que abarcan lo local, lo nacional y lo transnacional. Otra cuestión a considerar a la hora de hablar de los roles de género es la costumbre de la purdah, que Hussain ${ }^{47}$ define como una larga trayectoria en Bangladesh de restricciones de carácter "tradicional" en la movilidad y la vestimenta de las mujeres "bangladesíes" que tiende a normativizar la segregación sexual y la modestia femenina. Hussain indica que la purdah no es una costumbre absoluta ni monolítica en su significación, siendo concretada de formas muy diferentes.

Volviendo entonces a Lavapiés, estas convenciones sobre el género adoptan, entrelazadas al proceso de incorporación y los condicionantes que este acarrea (por ejemplo el enfoque de la sociabilidad o el manejo del idioma), una concreción que muchas veces acentúa la tendencia a la separación por el género, delimitando relaciones asociativas y trayectorias espacio-temporales diferenciales. Las "bangladesíes" se enfocan en aspectos concretos del cuidado de la familia: estar en casa por las mañanas, ir por los hijos/as al colegio, reunirse con las "paisanas" por las tardes mientras sacan a los niños al parque... Estas tareas convencionalmente asignadas a las mujeres muestran la migración como proceso generizado donde se concretan relaciones de poder que intersectan género, familia y ciclos individuales y sociales ${ }^{48}$. En estas dinámicas participan diferentes posiciones de sujeto dentro de redes asociativas con despliegues geográficos propios, generándose cotidianeidades distintas y diferentes formas de sentir el lugar ${ }^{49}$. Lavapiés se desarrolla de forma diferente para hombres "sin papeles" y mujeres que llegan por reagrupación familiar mientras la relación entre espacio, redes asociativas y poder se combina de diferentes maneras ${ }^{50}$ para producir diferentes cronotopías entre hombres y mujeres. Esto hace necesario un examen de al menos dos ámbitos espacio-temporales: el territorio y los usos que se realizan de él y la distribución espacial de las asociaciones. Ambas cuestiones se interrelacionan para formar diferentes espacio-tiempos, conformados individual-grupalmente en función de las posiciones de sujeto ocupadas. Diferentes personas van a enmarcarse en diferentes cronotopías, van tener experiencias espacio-temporales diferentes (por ejemplo el tránsito por Lavapiés y las horas en que este se realiza) que delimitarán a donde cada uno pertenece, qué es accesible a cada quien o cómo se confieren privilegios a algunos grupos.

46 Chowdhury, 2002.

47 Hussain, 2010.

48 Donato et al., 2006.

49 Harvey, 1994.

50 Massey, 2012b. 
Sin embargo, vista la diversidad que recoge el pequeño resumen sobre los estudios de roles de género en Bangladesh reseñado aquí, podemos decir que sobre las convenciones de género, familia o movilidad, ni todas las mujeres actúan igual, ni tendremos una única forma de configuración espacial posible. Como ejemplo está Nasima, que migró hace once años. Su marido tenía una empresa que le iba bien, pero luego enfermó y tuvo que cerrarla. Además, las cosas en Bangladesh "estaban muy mal con la política". No tenían dinero y estaban los hijos. Entonces migró a Inglaterra, ya que por la empresa de su marido tenía un visado que permitía ir y venir. Luego estuvo un tiempo en Bélgica y finalmente llegó a Madrid. Al principio no vivía en Lavapiés y tenía problemas con sus "paisanos" en el barrio: "no creían que yo estaba casada, me decían que estaba divorciada". A muchos no les parecía bien que se hubiera venido sola. Tampoco tenía "papeles". Todo esto la hacía sentirse sola. Trabajaba sin contrato limpiando casas y cuidando niños. Luego conoció a gente de varios grupos del barrio y a alguna "paisana" y las cosas mejoraron. Además, le ayudaron con los "papeles". Tardó cinco años en conseguirlos. Para esto le ayudó aprender castellano y unas clases que dio de cocina. Como no sabía español se ponía en primera fila, miraba lo que hacía la profesora y lo apuntaba todo. Tras varios años y varios proyectos para ganarse la vida, entre ellos una frutería en Parla que le salió bastante mal, pudo estabilizarse y "traer" a su marido y a una hija.

La historia de Nasima muestra un proceso de incorporación diferente al normativo en torno a la mujer, pero similar al masculino y con consecuencias similares en la modificación de redes asociativas. En este caso es Ben, su marido, quien, condicionado por su enfermedad, tiene más dificultades para moverse fuera del entorno "bangladesí" del barrio. También están presentes las principales categorías que guían el proceso de incorporación entre los hombres "sin papeles": el "conocer", el "mejorar" y la búsqueda del desarrollo económico y de la "tranquilidad" familiares, así como la existencia de redes asociativas más allá de lo "bangladesí" que, sin embargo, son surcadas por los condicionantes que acarrea el género: la extrañeza, incluso a veces el rechazo, de los "paisanos" a una mujer que migra sola. Este es un elemento que confirma la normatividad analizada en torno a la migración y el género y destaca otra cuestión que reafirma la presencia de esta convención: la presión grupal. Nasima refiere la soledad que la particularidad de su migración le ocasionó. Las convenciones en torno a la mujer "bangladesí" aparecen en el "cotilleo" que algunas de estas mujeres sienten sobre sus acciones, como por ejemplo Chandra y su madre, Dhurjati, que igual que Nasima, se alejan del modelo convencional presentado. Dhurjati no quiere quedarse en casa únicamente. Ha realizado prácticas cuidando ancianos y se apuntó a clases de castellano para poder valerse por sí misma. Chandra comenta que a ella y a su madre no les gusta demasiado relacionarse con otros "bangladesíes":

Sí, son muy aferrados a la cultura. No sé, son muy... pues mi cultura no, no, no abrirme. A mí lo que no me gusta, eso desde mi punto de vista, que siempre se critica muchísimo a las chicas. Esta chica ha hecho lo otro, esta chica va así, esta está en Facebook haciendo estas cosas. 
Y luego ves a los chicos que también hacen lo mismo y no se les critica. Es como ¿por qué?... y yo creo que eso ya no es parte... yo creo que eso ya es pensar... pensar como digo... sin cabeza, ¿no? Vale que chicas y chicos estamos separados en la cultura, que tenemos que ser de una forma y los chicos de otra, pero también creo que necesitamos el mismo respeto que se le ofrece a los chicos [...] a mi madre no le gusta juntarse mucho con la gente de Bangladesh... es que son muy cotillas. A mí tampoco me gusta. Si eso, hola qué tal, adiós... ya está... y tiene amigas, pero que son tres o cuatro, que son muy, muy conocidas, que llevan tiempo aquí, con las que ya tiene confianza. (Extracto del diario de campo del autor)

En Chandra y Dhurjati, los condicionantes sobre género y migración se concretan de manera diferente a la habitual en las mujeres que migran por reagrupación, no por un proceso migratorio diferente al de la mayoría de mujeres "bangladesíes", como en el caso de Nasima, sino a partir de la diversidad de posiciones de sujeto que se articulan en torno a la "mujer bangladesi", lo que origina formas de operar diferentes sobre las normatividades existentes, produciéndose diferentes configuraciones espacio-temporales dentro del proceso de incorporación. Otro ejemplo en este sentido es el de Nazma, que llegó a Barcelona para reagruparse con su marido y que durante el tiempo que estuvo con él, se relacionó sobre todo con mujeres "bangladesíes". Pero su divorcio le llevó a mudarse a Madrid en solitario, donde aprendió el idioma y realizó varios cursos, a la vez que su situación le encaminaba hacia organizaciones feministas y de defensa de la población migrante, a partir de las cuales comenzó a trabajar para la administración. Esto muestra, junto a las historias de Nasima, Chandra o Dhurjati, configuraciones socio-espaciales diversas en las características espaciales referidas anteriormente: movilidad, sentido del lugar y diferenciación geográfica. Vemos entonces que los espacio-tiempos de los y las bangladesíes en Lavapiés no son sólo diferentes por género, sino que, entre mujeres se producen diferencias dentro de la aceptación o discusión sobre determinadas centralidades hegemónicas. Chandra, por ejemplo se queja de la imposibilidad de las mujeres de poder asistir a la mezquita y así enterarse de lo que se habla allí y al salir del rezo:

Chandra: Claro, porque... las mujeres no pueden ir a la mezquita, mi madre a veces se queja, dice: venga todo para hombres y para mujeres nada, y se queja un montón.

Autor: Pero a la mezquita, si hay separación, sí pueden ir mujeres ¿no?

Chandra: sí, pero es que aquí no hay separación. En la de la M30, que no sé quién la ha hecho, es muy grande la mezquita, ahí si hay para mujeres, pero aquí no. Es más eso: que las mujeres se queden en casa a rezar y los chicos se queden en la mezquita

Dentro del entorno analizado, los tiempos de los hombres se relacionan con ir a vender o trabajar, reunirse en diferentes colectivos del barrio, acudir a la mezquita... hay mayor frecuencia en la relación con no "bangladesíes"... se producen cronotopías cotidianas que son diferentes de las de las mujeres: la casa, recoger a los niños, ir a ayudar en el negocio del marido... Pero la diferencia en los modos de incorporación de otras mujeres acarrean espacio-tiempos diferentes donde aparecen otras asociaciones, otras amistades, otros territorios que transitar que aportarán diferentes sentidos del lugar sobre el barrio. Es en el espacio donde se producen estas 
diferencias y donde se forma el cronotopo, que Cruces $^{51}$ presenta como una forma de unir espacio y tiempo en las lógicas concretas de determinados agentes, permitiendo observar la acción localizada como una configuración específica que producirá diferentes formas de entender espacios y tiempos, diferentes cronotopías donde se aglutinan procesos de largo alcance (convenciones en torno al género, legislación migratoria, circunstancias familiares...) concretándose en posibilidades diferentes de significado que ligan lo cercano y lo lejano a partir de cómo lo espacial contribuye a estructurar el tiempo. Los diferentes procesos de incorporación presentados aquí plantean por tanto diferentes cronotopías relacionadas con los condicionantes que acarrea la migración y el género. Estos cronotopos engarzan los territorios surcados con las redes de asociaciones que forman parte de la vida de diferentes personas. Espacio-tiempos de la cotidianeidad que extienden su geografía a otros entornos que van más allá del barrio de Lavapiés. Aunque no se transiten físicamente, aquellas localidades de Bangladesh que son los orígenes migratorios se introducen en los cronotopos, no sólo desde el contacto frecuente con la familia o los amigos en otros territorios, percibidos por los migrantes como parte de su cotidianeidad, sino como elementos condicionantes del proceso de incorporación y, como tal, de parte de sus vidas, ligados al recuerdo y a las emociones, productos de la vivencia en determinadas redes de asociaciones. Desde este punto de vista, no es tan raro afirmar que Bangladesh es Cuenca.

\section{Discusión: Volviendo a los modos de incorporación}

La relación entre cronotopías y redes asociativas nos lleva de nuevo a los modos de incorporación. Los extensos debates en torno a esta categoría han recogido abundantes y diversas reflexiones, como puede ser la posibilidad de comprender cómo los elementos estructurales influyen en los procesos de asentamiento, afectando a quién migra y sus descendientes en función del grupo de pertenencia y contexto al que se incorporan ${ }^{52}$. También, la forma de asignar diferentes modos a distintos grupos migrantes y la posibilidad de operacionalizar estos modos comparativamente para analizar las diferencias encontradas ${ }^{53}$. O la posibilidad de establecer un número de variables fijas a analizar a la hora de operar analíticamente con los modos de incorporación, es decir: qué afecta al proceso de incorporación y si esto es constante en todas las migraciones ${ }^{54}$. Por último, la relación entre modos de incorporación y nacionalismo metodológico, dado al uso del origen nacional como forma de aproximación más habitual en estos estudios ${ }^{55}$.

Para reflexionar sobre estas cuestiones comenzaré recordando que la incorporación no es igual para cada "bangladesí", condicionado este proceso por la posición en diferentes redes de asociaciones donde encontraremos desde relaciones de apo-

51 Cruces, 1997.

52 Waldinger y Catron, 2016.

53 Massey et al., 2008; Waldinger y Catron, 2016.

54 Freeman, 2006; Morawska, 2014.

55 Grosfoguel, 1999; Levitt y Glick Schiller, 2004; Waldinger y Catron, 2016 
yo mutuo y amistad hasta transmisión de normatividades hegemónicas en torno a diferentes cuestiones, tales como la "musulmanidad", el género o los objetivos migratorios. Además, estas redes son procesuales y los cambios en ellas influirán en el modo de incorporación y en la formación de cronotopías cotidianas. Y las redes de cada uno pueden solaparse parcialmente con las de otros formando campos asociativos que conectan de manera compleja a personas que no están relacionadas directamente y que se localizan territorialmente en puntos diferentes. El análisis centrado en estos campos asociativos y su despliegue geométrico puede alejarnos de miradas de contenedor y de conceptualizar el mundo como un mosaico de culturas a partir de ordenes legales hegemónicos ${ }^{56}$, llevándonos a procesos espacializados donde existen diferentes posiciones de sujeto que pueden traducirse en cronotopías diferenciales. Esto no impide la transmisión de normatividades, por ejemplo sobre cómo ser migrante, sujeto generizado y "bangladesí": el hombre migra primero porque es "peligroso" y difícil, por la idea de mejora familiar asignada a roles de género, mientras que estos mismos roles ocasionan una mayor frecuencia de migración femenina dentro de la reagrupación y la orientación de la sociabilidad de la mujer hacia los "paisanos", el cuidado y la familia. Esta normatividad no es automática, pues se articula a partir de la diversidad posicional y la posibilidad de negociarla o negarla. También se modifica por la influencia de diferentes condicionantes, por ejemplo la legislación migratoria que afecta al proceso migratorio. O las lógicas de creación y mantenimiento del estado-nación y de su gobierno, que ofrecen articulaciones hegemónicas donde se producen clasificaciones que ligan espacio e identidad dentro de diferentes políticas de control económico y poblacional ${ }^{57}$. Un ejemplo de esto son las regulaciones de fronteras, que nos remiten a un mapa surcado de relaciones de poder allí donde las líneas divisorias demarcan sentimientos de pertenencia y adscripciones, asociando cultura y territorio y naturalizando el estado nación, entre otros marcadores espacio-culturales, como forma natural de delimitación ${ }^{58}$. Lógicas gubernamentales y visiones de contenedor producen movimientos clasificadores que otorgan identificaciones preeminentes sobre otras posibilidades de ser. Así, una determinada concepción espacial se normativiza, desplegada dentro de discursos de amplia difusión que no tienen únicamente efecto simbólico. Las fronteras no son líneas en el mapa, sino que se traducen en muros, en policías, en muertes de personas tratando de llegar a Europa... y no desaparecen al cruzarlas, pues residen en las lógicas clasificatorias de las personas señalando al otro, al extranjero, y conformando de muchas maneras su día a día (por ejemplo, negándole la posibilidad de trabajar de manera "legal").

La deconstrucción de estas lógicas, una cuestión moral y metodológica, obliga a evitar la reificación del origen en el análisis de la incorporación, trabajando dentro de la tensión entre las dinámicas que determinados condicionantes estructurales

56 Hiernaux y Zárate, 2008.

57 Gupta y Ferguson, 1997.

58 Gupta y Ferguson, 1997; Portes y DeWind, 2006. 
aportan al proceso de incorporación y la vocación a mostrar las particularidades que diferentes procesos migratorios originan en diferentes personas. En la definición de Portes ${ }^{59}$ aquellos condicionantes que definen el modo de incorporación serían las políticas gubernamentales, el mercado laboral, la población nativa vecina y la propia comunidad ya pre-establecida. Sin dejar de subrayar la lógica de estos condicionantes, mi planteamiento se centra en dar la vuelta a esto para buscar en lo empírico tanto lo que específicamente y en diferentes grados afecta a quienes migran como lo que se torna significativos para ellos. Partiendo de clasificaciones preestablecidas, corremos el riesgo de proyectar sobre lo empírico patrones que se correspondan más con las categorías de las ciencias sociales que con lo que observamos en nuestras investigaciones ${ }^{60}$. Operar, por tanto, con una serie de categorizaciones excesivamente apriorísticas puede contribuir a reificar determinadas categorías y privilegiar una forma de observar la incorporación que, como indica Freeman ${ }^{61}$, está todavía muy presente en los estudios de migraciones: una mirada que sigue manteniendo trazos asimilacionistas, que parte de un movimiento direccional similar al de meter algo en un vaso, lo que por un lado contribuye a perpetuar la dicotomía nativo-extranjero, y, por otro, permite extender el proceso de incorporación a segundas y terceras generaciones, de manera que los descendientes de migrantes siguen siendo considerados como parte de la migración, convirtiendo, el proceso de incorporación en una especie de condena en la que tienen que pasar muchos años para que los descendientes de quién migró pasen a ser parte del entorno de destino.

Una perspectiva que parta del análisis de redes socio-espaciales concretas puede mostrarnos que incorporación no es sinónimo de "integración", sino que se despliega en otro sentido, en el de la modificación de las redes de asociaciones en la que cada uno se integra. La incorporación es una forma de significar un cambio de territorio físico y las consecuencias que este acarrea, teniendo en cuenta que la modificación asociativa es constante, no ligada sólo a la migración, y que, como hemos visto aquí, la asociación con nodos localizados en el destino puede ser previa a la incorporación, no está únicamente ligada a esta. Esto tiene dos consecuencias. Primero, que el estudio de la incorporación se extiende únicamente a quien migra como manera de señalar los cambios que la migración produce. Es decir, se trata de examinar la llegada al nuevo destino, no de reificar al migrante y sus descendientes como ajenos al "nativo". Segundo, al hablar de "políticas de integración": sin olvidarnos de las posibles discriminaciones que las características fenotípicas o las identificaciones en torno a un determinado origen o "etnicidad" tienen para determinadas "colectividades", la propuesta es separar nuestra lógica de investigación de aquello que, a partir de lo empírico, interpretamos que tiene sentido para las personas en un determinado entorno. Nos moveríamos en dos planos interconectados donde tratamos a la vez de no reificar nuestro análisis y de recoger aquello que es significativo

59 Portes, 1981; Portes y Böröcz, 1989.

60 Latour, 2008.

61 Freeman, 2006. 
para los agentes en el campo. Esto nos permitirá trabajar contemplando a quien migra como integrado en unos determinados campos asociativos que no tienen que ver sólo con la migración, a la vez que poder pensar en la "integración" como una forma concreta de política, con resultados que tienen sentido en un entorno determinado y acarrean una serie de consecuencias.

Además, habría que subrayar otras posibles modos de incorporación dentro de lo "bangladesí" en Lavapiés no tratados en este texto. Por ejemplo, quienes migran de manera "legal", o lo hacen de manera "ilegal" pero tienen familiares aquí que facilitan la llegada. O quienes no se relacionan con agrupaciones de defensa de la población migrante y encaran su sociabilidad a otros lugares. También profesionales altamente cualificados, o niños/as que llegan al barrio muy pequeños o adolescentes. Las condiciones de vida de los "bangladesíes" en Lavapiés son diversas. Desde gente "con mucha pasta", dueños de varios comercios, a "sin papeles" que se ganan la vida en la venta ambulante, pasando por quien regulariza su situación y monta un negocio con el que "va tirando". También hay diferencias entre quienes comparten una misma forma de incorporación. Nahir y Hossain, ambos compañeros de Migrapiés, afrontan situaciones diferentes: Nahir llegó hace siete años y en ese tiempo consiguió regularizar su situación y abrir un restaurante. Hossain lleva más de diez años en España y todavía no tiene "papeles", a pesar de intentarlo varias veces, por lo que sigue trabajando vendiendo en la zona centro de Madrid. Todas estas variaciones no pueden verse como etapas de un mismo proceso, sino a partir del analisis de posiciones de sujeto diferenciales ligadas a los condicionantes originados por el proceso de incorporación. Y estas posiciones se demarcan a partir de diferentes cuestiones: edad, género, educación, relaciones, región, nivel socio-económico previo a la migración... también la suerte, las habilidades personales, el conocer a diferentes personas, la capacidad de trabajo, las prioridades del proyecto migratorio... Así, otro argumento para no basarse excesivamente en categorías apriorísticas en el análisis de la incorporación es el de la cantidad de variables intervinientes en este proceso y la variabilidad de estas en un entorno y entre diferentes entornos, lo que hace difícil plantear teorías que recojan todos los factores intervinientes. La cuestión está en lo problemático de abarcar objetivamente todo lo que influye en la incorporación y a partir de ahí establecer alguna tipología de los modos de incorporación, pensando quizá que la complejidad de la migración requiere teorizaciones parciales donde haya diferentes puntos de vista ${ }^{62}$.

A partir de la imposibilidad de captar variaciones tipológicas fijas de los modos de incorporación y atendiendo a la diversidad y a la tensión entre los condicionantes estructurales del proceso migratorio y las diferentes concreciones de estos en diferentes particularidades, la definición propuesta de modos de incorporación pretende recoger la llegada de los migrantes al nuevo entorno y los cambios producidos en sus vidas en este proceso, teniendo en cuenta que esto no define a las personas, sino que es una más de las dinámicas vivenciales de cada uno. Esta definición pretende acer-

62 Massey et al., 2008. 
carse a la idea inicial de Portes de captar cómo quien migra es afectado/a por una serie de condicionantes a partir de los cuales se producen respuestas agenciales en función de una serie de variables contextuales donde la búsqueda de modos de incorporación debe estar abierta a la diversidad63 dentro de un marco teórico proclive a seguir los rastros de la acción social en nuestro entorno de estudio. Hablaremos entonces de modos de incorporación para observar los cambios originados por el proceso migratorio a partir del análisis de tres categorías entrelazadas: los condicionantes estructurales que afectan al proceso, la concreción diferencial de estos condicionantes en diversas posiciones de sujeto y las respuestas a estos condicionantes originando acciones, resistencias, adaptaciones... a partir de las que se producirán modificación de redes asociativas, teniendo en cuenta la especificidad de estas redes y los aspectos que a priori no tienen por qué tener que ver con las políticas sobre migración64.

\section{A modo de conclusión}

En este texto he tratado de conceptualizar la especificidad asociativa-geográfica para acercarnos a entornos que no sean pensados como contenedores enmarcados los unos en los otros, sino como formaciones espacio-temporales concretas producidas en la interacción. Esto me ha llevado a un análisis de diferentes cronotopos cotidianos y como se relacionan con las diferencias en el modo de incorporación, subrayando así la importancia del análisis espacio-temporal del proceso migratorio. Estas cronotopías aportan un mínimo de dos dimensiones a considerar en el análisis: la de los tránsitos de la cotidianeidad y los sentidos del lugar originados y la de las redes de asociaciones que se entrelazan con ellos. A partir de aquí, destaco la dificultad de un análisis que se centre en el origen nacional como elemento principal en la delimitación de los modos de incorporación, algo que no significa dejar de examinar aquellas convenciones sobre "nacionalidad" u origen que se muestran significativas en las vidas de los migrantes. Lo expuesto nos lleva una definición abierta de los modos de incorporación que no busca una tipología universal de aplicación en todos los casos, sino un marco teórico-metodológico que permita analizar la especificidad de entornos concretos y como se producen estos procesos de incorporación.

Otro aspecto del que podemos hablar a partir de este texto es aquel que se refiere al tópico de la mujer "musulmana" sumisa. Lo descrito sirve para evidenciar que las mujeres son agentes activos que, pese a la existencia de opresión en base al género, e incluso a pesar de poder estar de acuerdo con determinadas dinámicas que causan esta opresión, elaboran, con los recursos de los que disponen, sus propias maneras de vivir y diferentes formas de resistencia (incluyendo la decisión sobre aquello contra lo que resistir). Lo observado en mi entorno de trabajo indica una tendencia a la división socio-espacial en base al género. Los hombres en las asociaciones, en las mezquitas y en los comercios. Las mujeres en el hogar, en el parque con los niños y

63 Waldinger y Catron, 2016.

64 Freeman, 2006. 
si es en el comercio, en el de la familia. Estas diferencias se muestran acompañadas de una reflexión: no se trata de estereotipar a todos los "bangladesíes", formando una imagen que oculta las propias relaciones de opresión de género de "los de aquí" a partir de la idea de que es cosa de la "cultura" o la "religión". La presencia de personas "religiosas" o con fuerte apego a su "cultura" y a la vez contrarias a determinadas prácticas de opresión ya es un indicio de que caer en estos estereotipos puede ser estar confundiendo el síntoma con la causa. Si consideramos como diversos condicionantes influyen en la incorporación de hombres y mujeres "bangladesíes" y que las normatividades hegemónicas encontradas en el análisis no determinan el comportamiento, que las personas interpretan las convenciones sociales y en último término deciden en un proceso constante de cambio donde las reglas sociales son usadas por los agentes, podemos pensar que es en la existencia de relaciones de desigualdad y en las dinámicas de mantenimiento de estas donde se encuentra la dominación patriarcal, que además se retroalimenta con otros procesos hegemónicos colonialistas, imperialistas o capitalistas. La opresión no se encuentra por tanto en una jaula cultural, sino en las políticas públicas, en la gestión socioeconómica de la diversidad y en discursos hegemónicos recreados de forma continua sobre la "cultura", la "religión", la "tradición" o la "identidad".

\section{Bibliografía}

ARA, Raushan. Normative and institutional responses to torture in Bangladesh. Dhaka: University of Dhaka, Departament of Law, 2015 http://hdl.handle. net/123456789/785.

BASCH, Linda; GLICK-SCHILLER, Nina; SZANTON BLANC, Christina. Nations unbound: Transnational projects, postcolonial predicaments, and deterritorialized nation-states. New York: Routledge, 2005.

CAÑEDO RODRÍGUEZ, Montserrat. Lavapiés, área de rehabilitación preferente:Políticas culturales y construcción del lugar. Tesis doctoral inédita, Facultad de Ciencias Políticas y Sociología Universidad Complutense de Madrid, 2005.

CAÑEDO RODRÍGUEZ, Montserrat. Discursos vecinales sobre la inseguridad ciudadana y políticas de rehabilitación urbanística: el caso de los antiguos vecinos y la ARI-Lavapiés (Madrid) desde una perspectiva antropológica. Scripta Nova: Revista Electrónica De Geografía Y Ciencias Sociales, 2011, Vol. XV, no. 385. http://www.ub.edu/geocrit/sn/sn-385.htm

CARRETERO, Nacho. Lavapiés, el barrio laboratorio. 2013. http://www.yorokobu.es/ lavapies [consulta: 15 de abril 2014]

CHOWDHURY, Elora. Research, Representation and Responsibility: Unraveling the Sixteen Decisions Perspective on 'Impoverished Bangladeshi Women'. International Feminist Journal of Politics, 2002, vol. 4, no. 3. p. 408-414 doi.org/10 $.1080 / 1461674022000031490$. 
CRUCES, Francisco. Desbordamientos. Cronotopías en la localidad tardomoderna. Política Y Sociedad, 1997, vol. 25. p. 45-58 http://europa.sim.ucm.es/compludoc/ AA?articuloId=690299.

DÍAZ DE RADA, Angel. Cultura, Antropología y otras tonterías. Madrid: Trotta, 2012.

DIRECCIÓN GENERAL DE INMIGRACIÓN. II plan Madrid de convivencia social e intercultural. Madrid: Ayuntamiento de Madrid, 2009.

DONATO, Katharine M., et al. A Glass Half Full? Gender in Migration Studies. International Migration Review, 2006, vol. 40, no. 1. p. 3-26. doi 10.1111/j.17477379.2006.00001.x

EADE, John. Class and Ethnicity in a Globalising City. Ethnologia Europea, 2006, vol. 34.p. 57

FAIZ RASHID, Sabina; AKRAM, Owasimand; STANDING, Hilary. Emerging Changes in Reproductive Behaviour among Married Adolescent Girls in an Urban Slum in Dhaka, Bangladesh. Reproductive Health Matters, 2006, vol. 14, no. 27. p. 151159 http://dx.doi.org.ezproxy.uned.es/10.1016/S0968-8080(06)27221-5.

FREEMAN, Gary. La incorporación de inmigrantes en las democracias occidentales. Migraciones Internacionales, 2006, vol. 4, no. 1. p. 131-156 http://meme. phpwebhosting.com/ migracion/rimd/coleccion_america_latina/repensando/ Repensando_5laincorporacion.pdf.

GARDNER, Katy; MAND, Kanwal. 'My Away is here': Place, Emplacement and Mobility Amongst British Bengali Children. Journal of Ethnic and Migration Studies, 2012, vol. 38, no. 6. p. 969-986.

GARDNER, Katy; AHMED, Zahir. Place, Social Protection and Migration in Bangladesh: A Londoni Village in Biswanath, 2006. Dhaka: Sussex Centre for Migration Research, Jahangirnagar University

GIJON PRIETO, Ignacio. Bangladesh: Informe General Sobre La Situación De Derechos Humanos. Madrid: CEAR, 2012

GLICK SCHILLER, Nina; ÇAĞLAR, Ayse. Displacement, Emplacement and Migrant Newcomers: Rethinking Urban Sociabilities within Multiscalar Power. Identities, 2016, vol. 23, no. 1.p. 17-34 doi.org/10.1080/1070289X.2015.1016520.

GROSFOGUEL, Ramón. Puerto Rican Labor Migration to the United States: Modes of Incorporation, Coloniality, and Identities. Review (Fernand Braudel Center), 1999. p. 503-521 http://www.jstor.org/stable/40241472.

GUPTA, Akhil; and FERGUSON, James. Más allá de la cultura": Espacio, identidad y las políticas de la diferencia. Antipoda. Revista De Antropología Y Arqueología, 1997, no. 7. pp. 233-256 http://www.scielo.org.co/scielo.php?script=sci_ arttext\&pid=S1900-54072008000200011.

HARVEY, David. La construcción social del espacio y del tiempo: una teoría relacional. Geographical Review of Japan, 1994, Vol 67 (Ser. B) No 2. p. 126-135. 
HASAN, Mubashar. The Geopolitics of Political Islam in Bangladesh. Harvard Asia Quarterly, 2012, vol. 14. p. 60-69 https://research-repository.griffith.edu.au/ bitstream/handle/10072/47246/80022_1.pdf?sequence=1.

HIERNAUX, Daniel; ZÁRATE, Margarita. Transnacionalismo, cultura y espacio: a manera de introducción. HIERNAUX, Daniel; and ZÁRATE, Margarita eds., Espacios y Transnacionalismo. México D.F: Universidad Autónoma Metropolitana, 2008, p. 9-22.

HUSSAIN, Naseem Akhter. Religion and Modernity: Gender and Identity Politics in Bangladesh. Women's Studies International Forum, 2010, vol. 33, no. 4. p. 325-333 http://dx.doi.org.ezproxy.uned.es/10.1016/j.wsif.2010.02.006.

JAWAID, Syed Tehseen; and RAZA, Syed Ali. Effects of Workers' Remittances and its Volatility on Economic Growth in South Asia. International Migration, 2016, vol. 54, no. 2. p. 50-68 doi:10.1111/imig.12151.

LACLAU, Ernesto; MOUFFE, Chantal. Hegemonia y estrategia socialista. Madrid: Siglo Veintiuno, 1987

LATOUR, Bruno. Reensamblar lo social. Buenos Aires: Manantial, 2008.

LEVITT, Peggy; GLICK SCHILLER, Nina.Perspectivas internacionales sobre migración: conceptuar la simultaneidad. Migración Y Desarrollo, 2004, vol. 3. p. 60-91 http:// www.redalyc.org/pdf/660/66000305.pdf.

MARCUS, George E. Ethnography in/of the world system: The emergence of multisited ethnography. Annual Review of Anthropology, 1995, Vol. 24, p. 95-1 17. http:// www.dourish.com/classes/readings/Marcus-MultiSitedEthnography-ARA.pdf

MASSEY, Doreen. Introducción: la geografía importa. ALBET, Abel; BENACH, Nuria eds., Doreen Massey: un sentido global del lugar. Barcelona: Icaria, 2012a, p. 95111.

MASSEY, Doreen. Un sentido global del lugar. ALBET, Abel; BENACH, Nuria eds., Doreen Massey: un sentido global del lugar. Barcelona: Icaria, 2012b, p. 112-129.

MASSEY, Douglas, et al. Teorías de migración internacional: una revisión y aproximación. Revista De Derecho Constitucional Europeo, 2008, vol. 5, no. 10. p. 435-478.

MATO, Ana María. La crisis política de Bangladesh y las próximas elecciones. ARI Real Instituto el Cano, Área: Asia/Pacífico, 2006, o.17/2006 http://realinstitutoelcano. org/wps/portal/!ut/p/a0/04_

MINISTERIO DE ASUNTOS EXTERIORES Y COOPERACIÓN. Bangladesh. Programa de encuentros con embajadores de España. Madrid: Ministerio de Asuntos Exteriores y Cooperación, 2013.

MONETTI, María Eugenia. Las migraciones internacionales y el proceso de integración en las sociedades de acogida: una mirada desde las teorías sociológicas contemporáneas. Fronteras, 2017, vol. 3, no. 2. pp. 7-42. 
MOOKHERJEE, Nayanika. Gendered Embodiments: Mapping the Body-Politic of the Raped Woman and the Nation in Bangladesh. Feminist Review, 201 1, vol. 98. p. 190 doi: $22610.1057 /$ fr.2011.32.

MORAWSKA, Ewa. Immigrant Transnationalism and Assimilation: A Variety of Combinations and the Analytic Strategy it Suggests. MORAWSKA, Ewa; JOPPKE, Christian eds., Toward assimilation and citizenship: Immigrants in liberal nationstates. New York: Springer, 2014, p. 133-176 doi.org/10.1057/9780230554795_6.

PINEDA, Varinia; PLAZA SANZ, Marta; LENDRINO TEJERINA, Iván; LARA HERNÁNDEZ-PINZÓN, María. Madrid, ciudad para compartir. Cuadernos de la EPIC número 1, Madrid: EPIC, 2011

PORTES, Alejandro; DEWIND, Josh. Un diálogo transatlántico: el progreso de la investigación y la teoría en el estudio de la migración internacional. PORTES, Alejandro; DEWIND, Josh eds., Repensando las migraciones. Nuevas perspectivas teóricas y empíricas. México: Universidad Autónoma de Zacatecas, 2006, p. 7-31.

PORTES, Alejandro. Convergencias teóricas y evidencias empíricas en el estudio del transnacionalismo de los inmigrantes. Migración Y Desarrollo, 2005, no. 4 http://www.redalyc.org/html/660/66000401/.

PORTES, Alejandro; RUMBAUT, Ruben G. Immigrant America. Berkeley: University of California Press, 1996.

PORTES, Alejandro; BÖRÖCZ, József. Contemporary Immigration: Theoretical Perspectives on its Determinants and Modes of Incorporation. International Migration Review, 1989. p. 606-630 doil 0.2307/2546431.

PORTES, Alejandro. Modes of Structural Incorporation and Present Theories of Labor Immigration. KRITZ, MM; KEELY, C Band TOMASI, SM eds., Global trends in migration: theory and research on international population movements. Staten Island, New York: Staten Island New York Center for Migration Studies of New York, 1981, p. 279-297.

PRIES, Ludger. Configurations of Geographic and Societal Spaces: A sociological proposal between 'methodological nationalism' and the 'spaces of flows'. Global Networks, 2005, vol. 5, no. 2. p. 167-190 http://onlinelibrary.wiley.com/ doi/10.1111/j.1471-0374.2005.00113.x/full.

ROZARIO, Santi. Outside the Moral Economy? Single Female Migrants and the Changing Bangladeshi Family. The Australian Journal of Anthropology, 2007, vol. 18, no. 2. pp. 154-171 http://search.proquest.com.ezproxy.uned.es/ docview/212594124?accountid=14609

SÁNCHEZ MOLINA, Raúl. Mandar a Traer. Antropología, Migraciones Y Transnacionalismo. Salvadoreños En Washington. Madrid: Universitas, 2005.

VARGAS, Susana. Young Migrants and Narratives of Belonging: Modes of Incorporation Beyond Borders. Frontera Norte, 2017, vol. 29, no. 58. p. 47-70. 
VELASCO, Honorio; DÍAZ DE RADA, Ángel. La lógica de la investigación etnográfica. Madrid: Trotta, 1997.

VERTOVEC, Steven. Conceiving and Researching Transnationalism. Ethnic and Racial Studies, 1999, vol. 22, no. 2. pp. 447-462. doi.10.1080/014198799329558.

WALDINGER, Roger; CATRON, Peter. Modes of Incorporation: A Conceptual and Empirical Critique. Journal of Ethnic and Migration Studies, 2016, vol. 42, pp. 23-54 doi.5310.1080/1369183X.2015.1113742.

(C) Copyright: Juan R. Méndez Méndez, 2018

(c) Copyright: Scripta Nova, 2018.

Ficha bibliográfica:

MÉNDEZ MÉNDEZ, Juan R. Cronotopías en torno al género. Modos de Incorporación diferenciales entre "bangladesíes" en Lavapiés. Scripta Nova. Revista Electrónica de Geografía y Ciencias Sociales. Barcelona: Universidad de Barcelona, 1 de agosto de 2018, vol. XXII, nº 595. [ISSN: 1138-9788]. 